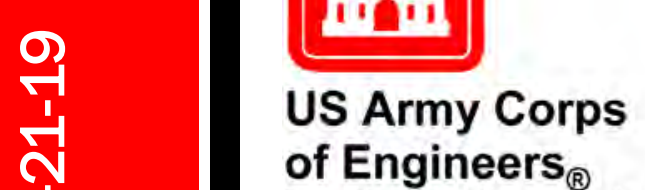

Engineer Research and

Development Center

\title{
Terrain Coefficients for Predicting Energy Costs of Walking over Snow
}

Paul W. Richmond, Adam W. Potter, David P. Looney, and

August 2021

William R. Santee 
The U.S. Army Engineer Research and Development Center (ERDC) solves the nation's toughest engineering and environmental challenges. ERDC develops innovative solutions in civil and military engineering, geospatial sciences, water resources, and environmental sciences for the Army, the Department of Defense, civilian agencies, and our nation's public good. Find out more at www.erdc.usace.army.mil.

To search for other technical reports published by ERDC, visit the ERDC online library at https://erdclibrary.on.worldcat.org/discovery. 


\section{Terrain Coefficients for Predicting Energy Costs of Walking over Snow}

Paul W. Richmond

Cold Regions Research and Engineering Laboratory

U.S. Army Engineer Research and Development Center

72 Lyme Road

Hanover, NH 03755

William R. Santee

Oak Ridge Institute for Science and Education (ORISE)

1299 Bethel Valley Road

Oak Ridge, TN, 37830

Adam W. Potter and David P. Looney

Biophysics and Biomedical Modeling Division

U.S. Army Research Institute of Environmental Medicine

Natick, MA, 01760

Final report

Approved for public release; distribution is unlimited.

Prepared for U.S. Army Corps of Engineers

Washington, DC 201314

Under U.S. Dept. of Energy and ERDC Interagency Agreement 


\section{Preface}

This study was conducted for the U.S. Army Corps of Engineers and was supported in part by appointments to the Knowledge Preservation Program of Dr. Richmond at the U.S. Army Engineer Research and Development Center, Cold Regions Research and Engineering Laboratory (ERDC-CRREL) and Dr. Santee at the U.S. Army Research Institute of Environmental Medicine administered by the Oak Ridge Institute for Science and Education through an interagency agreement between the U.S. Department of Energy and ERDC-CRREL.

The work was performed by the U.S. Army Engineer Research and Development Center, Cold Regions Research Engineering Laboratory (ERDCCRREL). At the time of publication, the Deputy Director for ERDC-CRREL was Mr. David Ringelberg and the Director was Dr. Joseph Corriveau.

This paper was originally published online in Applied Ergonomics on 15 August 2018.

The Commander of ERDC was COL Teresa A. Schlosser and the Director was Dr. David W. Pittman.

DISCLAIMER: The contents of this report are not to be used for advertising, publication, or promotional purposes. Citation of trade names does not constitute an official endorsement or approval of the use of such commercial products. All product names and trademarks cited are the property of their respective owners. The findings of this report are not to be construed as an official Department of the Army position unless so designated by other authorized documents. 


\title{
Terrain coefficients for predicting energy costs of walking over snow
}

\begin{abstract}
A B S T R A C T
Background: Predicting the energy costs of human travel over snow can be of significant value to the military and other agencies planning work efforts when snow is present. The ability to quantify, and predict, those costs can help planners determine if snow will be a factor in the execution of dismounted tasks and operations. To adjust predictive models for the effect of terrain, and more specifically for surface conditions, on energy costs, terrain coefficients $(\eta)$ have been developed. The physiological demands of foot travel over snow have been studied previously, and there are well established methods of predicting metabolic costs of locomotion. By applying knowledge gained from prior studies of the effects of terrain and snow, and by leveraging those existing dismounted locomotion models, this paper seeks to outline the steps in developing an improved terrain coefficient $(\eta)$ for snow to be used in predictive modeling.

Methods: Using published data, methods, and a well-informed understanding of the physical elements of terrain, e.g., characterization of snow sinkage (z), this study made adjustments to $\eta$-values specific to snow.

Results: This review of published metabolic cost methods suggest that an improved $\eta$-value could be developed for use with the Pandolf equation, where $z=$ depth $(h)^{*}\left(1-\right.$ (snow density $\left.\left(\rho_{0}\right) / 1.186\right)$ ) and $\eta=0.0005 z^{3}+0.0001 z^{2}+0.1072 z+1.2604$.

Conclusion: While the complexity of variables related to characteristics of snow, speed of movement, and individuals confound efforts to develop a simple, predictive model, this paper provides data-driven improvements to models that are used to predict the energy costs of dismounted movements over snow.
\end{abstract}

\section{Introduction}

Activities in snowy environments generally require more energy than similar activities in more moderate or warm conditions. Day et al. (2012) indicated that the increased demand could be up to $20 \%$, further stating: "increase in total caloric requirements is mainly caused by increased physical exertion, because it is unlikely that cold exposure itself, in an adequately clothed individual, increases energy requirements more than 10\%". Baker-Fulco (1995) suggested that due to the increased energy requirements, military personnel may be unable to maintain adequate caloric intake in the cold.

Physiological studies of dismounted movement in snow typically characterize snow conditions descriptively. This may be due to the fact that snow is difficult to quantify. Even at present, measurement of snow properties, such as snow fall and depth, use relatively simple instruments and methods. A dated $(60+\mathrm{yr})$ Snow, Ice and Permafrost Research Establishment (SIPRE) Instruction manual (SIPRE, 1954) describes a snow kit for measuring snow properties. With only a slight change to the spring scales, the same kit and the same observations are still in use today. The key properties of snow include depth $(h)$, sinkage $(\mathrm{z})$, slipperiness, and strength or density $(\rho)$; which is closely related to moisture content and grain characteristics.

The terrain coefficient $(\eta)$ was developed to adjust human energy cost predictions for different surface conditions. The concept of $\eta$ for dismounted movements and load carriage was introduced by Givoni and Goldman (1971) and defined more clearly by Soule and Goldman (1972). Richmond et al. (2015) reviewed and refined $\eta$ for common surface conditions (e.g., pavement, gravel, packed dirt, sand, and mud). By exploiting existing knowledge of snow properties and surface physics derived from vehicle locomotion studies can be used to develop improved $\eta$-values for snowy terrain.

The essential research on $\eta$ for physiological modeling was conducted 1972-1979 at the US Army Research Institute of Environmental Research (USARIEM) and translated into usable models. This paper 


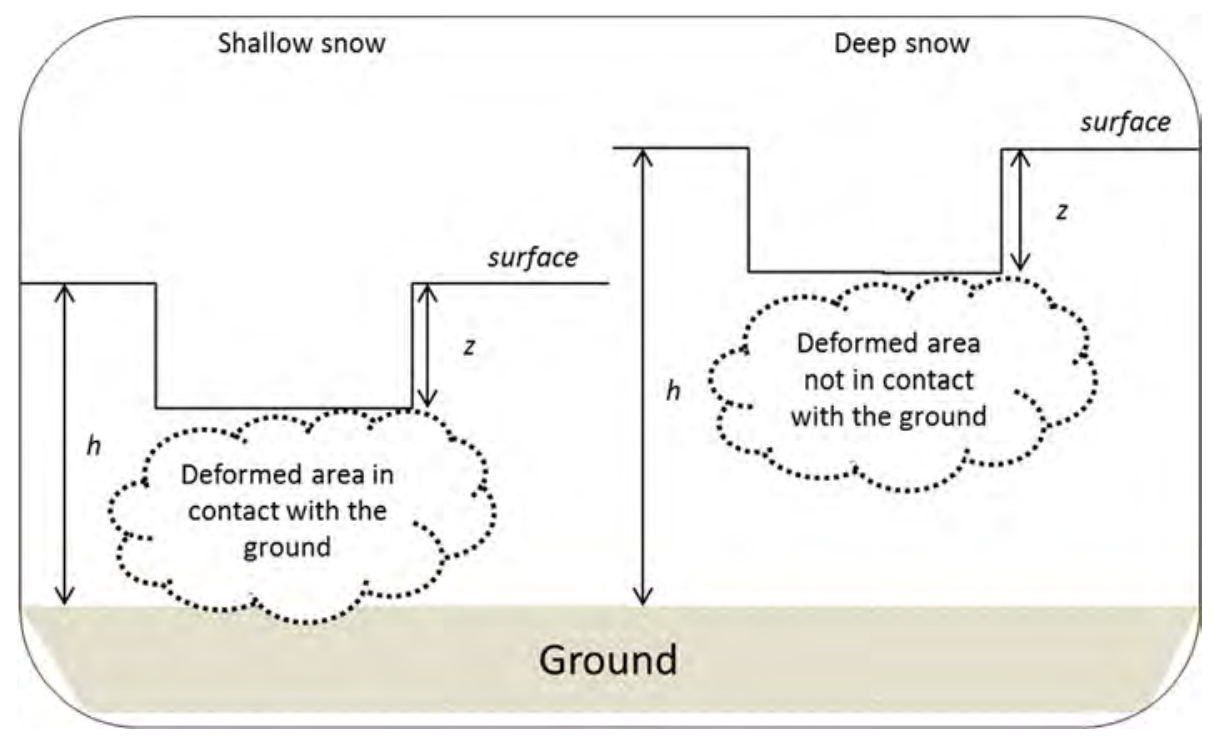

Fig. 1. Deep and shallow snow, determined by interaction of deformed snow with the ground.

briefly reviews the existing USARIEM equations for prediction of energy cost of walking, the origin of $\eta$, and then refines $\eta$-values specific to snow using knowledge of snow and surface physics from vehicle locomotion studies, and existing data from multiple human studies of snow walking.

\section{Materials and methods}

\subsection{Load carriage models}

From 1971 to 2003, several load carriage models were developed at USARIEM. These models incorporate multiple parameters, including terrain, to determine the energy cost of load carriage. A brief overview of the most relevant models is presented and a more detailed description of these models and how are used to evaluate and refining terrain coefficients is presented in Richmond et al. (2015).

Equation (1) was developed by Givoni and Goldman (1971):

$\mathrm{M}=\eta(\mathrm{W}+\mathrm{L})\left[2.3+0.32(\mathrm{~V}-2.5)^{1.65}+\mathrm{G}(0.2+0.07(\mathrm{~V}-2.5))\right]$

where $M$ is the metabolic rate $\left(\mathrm{kcal}^{-1} \mathrm{~h}^{-1}\right), W$ is body mass $(\mathrm{kg}), L$ is the external load (kg), $V$ is the velocity or speed of walking $\left(\mathrm{km} \cdot \mathrm{h}^{-1}\right)$ and $\eta$ is a non-dimensional terrain coefficient. For the purposes of this paper, the most important aspect of Givoni and Goldman (1971) is the introduction of the terrain coefficient $(\eta)$. The concept of $\eta$ is based on a relative scale, using a non-dimensional (ND) $\eta$ value of 1.0 for walking on a treadmill; while a proposed initial $\eta$ value of 1.6 was suggested for hard snow.

The first improved list of $\eta$ values is Soule and Goldman (1972). The $\eta$-values developed by Soule and Goldman (1972) were for level terrain in the context of Givoni and Goldman (1971). As described in Richmond et al. (2015), a modified version of Eq. (1) was developed for level ground, the basis for all of the Soule and Goldman (1972) $\eta$-values, by setting $\mathrm{G}=0 \%$, adjusting for different units for $V\left(\mathrm{~m} \cdot \mathrm{s}^{-1}\right)$ and $M(\mathrm{~W})$ :

$\mathrm{M}=\eta(\mathrm{W}+\mathrm{L})\left[2.673+3.078(\mathrm{~V}-0.694)^{1.65}\right]$

Using elements from Givoni and Goldman (1971), Pandolf et al. (1977) presented a refined equation of metabolic cost:

$M=1.5 W+2.0(W+L)\left(\frac{L}{W}\right)^{2}+\eta(W+L)\left(1.5 V^{2}+0.35 V G\right)$

where variables are the same as those from Givoni and Goldman (Eq.
(1)) except for different units in $M(\mathrm{~W}), V\left(\mathrm{~m} \cdot \mathrm{s}^{-1}\right)$, and the addition of grade $(G)$ for the uphill slope or gradient (\%).

The equation from Pandolf et al. (1977) is currently the more widely recognized model for predicting energy costs of load carriage. Later models from Pimental and Pandolf (1979), addressed a primary limitation of the Pandolf et al. equation (Eq. (3)), indicating it did not address negative (downhill) grades. To address the downhill grade limitation of the Pandolf et al. (1976) equation, Santee et al. (2003) developed a correction factor (CF) for Eq. (3):

$\mathrm{CF}=\eta\left[\mathrm{G}(\mathrm{W}+\mathrm{L}) \mathrm{V} / 3.5-\left((\mathrm{W}+\mathrm{L})(\mathrm{G}+6)^{2}\right) / \mathrm{W}+\left(25-\mathrm{V}^{2}\right)\right]$ form:

This CF is intended for use when the slope is $\leq 0$ in the following

$\mathrm{M}=\mathrm{Eq} \cdot 3-\mathrm{CF}$

\subsection{Terrain coefficient for snow}

\subsubsection{Walking in shoes or boots}

In addition to load carried and grade, there are other parameters that can influence the work rate and walking velocity. In snow, these parameters include snow depth $(h)$, density $(\rho)$, slipperiness (traction), and type and weight of footwear and winter clothing.

Snow depth and the amount a person sinks into the snow are important relative to the effort required to walk in it. In Fig. 1, shallow snow is presented as a combination of snow density and the depth where the layer of snow that is deformed or compacted by stepping on it reached the ground, essentially producing firm resistance against further sinkage and provides a firmer surface to push of/against to move forward. In deep snow, the deformed layer is not in contact with the ground, and more or less floats above un-deformed snow, so there is more potential to sink further overtime, or more pressure associated with a heavier load.

Skis and snowshoes were developed specifically to make movement over snow covered surfaces easier by reducing sinkage, as even moderate reductions in sinkage can reduce energy costs. However, predicting sinkage is difficult, as it is dependent on both snow $h$ and $\rho$. Haehnel and Shoop (2004) outlined snow response to load and issues associated with describing snow $\rho$. Describing snow $\rho$ is not a well-defined process, though there are several indices which can be used.

If it is assumed when walking in snow the front half of the foot supports the entire walker's mass during each step, and represents the 


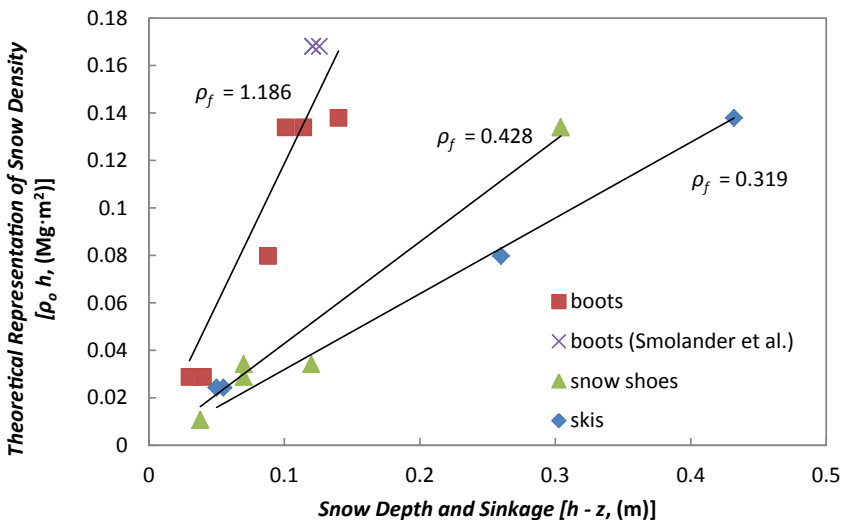

Fig. 2. Snow sinkage is related to the original $\left(\rho_{o}\right)$ and final, or compacted $\left(\rho_{f}\right)$ snow densities, and the original $(h)$ and final $(z)$ snow depths for movement in snow using boots, snowshoes and skis. Differences in pressure (force per unit area) for boots, snowshoes and skis result in differences in deformation of the snow, and $\rho_{f}$ and $z$-values.

highest pressure, an estimate of $52 \mathrm{kPa}$ of "foot" pressure. This value being calculated based on methods used on tracked vehicle ground pressures from Richmond et al. (1995) in the following two equations estimating vehicle sinkage:

$z=h\left(1-\frac{\rho_{0}}{\rho_{f}}\right)$

where: $h=$ snow depth $(\mathrm{cm}), \rho_{0}=$ undisturbed (initial) snow density $\left(\mathrm{Mg} \cdot \mathrm{m}^{3}\right)$, and $\rho_{f}=$ theoretical final snow density $\left(\mathrm{Mg} \cdot \mathrm{m}^{3}\right)$, for pressures under $210 \mathrm{kPa}$, a value of $0.5 \mathrm{Mg} \mathrm{m}^{3}$ is specified (for tracked vehicles).

For wheeled vehicles:

$\rho_{f}=0.19+0.0023 p_{\max }$

where $p_{\max }$ is the maximum contact pressure (kPa) (Richmond, 1995). Rearranging Eq. (6) such that $\rho_{f}$ represents the slope in a linear equation yields:

$\rho_{0} h=(h-z) \rho_{f}$

The modified equation, Eq. (8), allows the determination of $\rho_{f}$ by regression analysis. Fig. 2, presents $z$ data from Richmond (1984) and Smolander et al. (1989), for boots, snowshoes and skis, with $\rho_{f}$ estimates for each footwear condition. As snow $h$ and $\rho$ are available from terrain state models, Eq. (6) combined with the values of $\rho_{f}$ in Fig. 2 can provide estimates of $z$.

On further consideration of Fig. 2 and our observations, the value of $\rho_{f}$ for snowshoes is only applicable to "shallow" snow. However, snowshoes are only needed in "deep" snow conditions (Fig. 1). In most cases, once a trail is broken, when properly sized, snowshoes only sink $\sim 1-6 \mathrm{~cm}$, regardless of snow conditions. Fig. 2 indicates that when the potential for the depression of snow $(h-z)$ is small, the values for boots, snowshoes, and skis converge; thus making their use less beneficial. Fig. 1 describes that in shallow snow, especially if it is already compacted by trail breaking, the close proximity of the ground surface limits the potential for further compaction. In deep snow, sinkage is not limited by proximity to the ground surface, so there is more potential for additional sinkage and therefore the distribution of downward force (pressure) over a greater surface area, the "float" provided by snowshoes or skis becomes more beneficial. Unless the snow is deeper than "boot tops" ( $\approx 25 \mathrm{~cm}$ ) snowshoes should probably not be used. A similar effect will be observed for travel on skis.

Pandolf et al. (1976) conducted walking in snow experiments, measuring depression (sinkage), and also "snow-water" content measurements, but that data was not reported. They presented the following $\eta$ for snow, for use with Eq. (1): $\eta=1.30+0.082 z$

where $z$ is equal to the sinkage $(z)$ into the snow $(\mathrm{cm})$.

Examination of this equation, which relies heavily on empirical data, raises some questions as to its applicability:

- As $z$ approaches 0, $\eta$ will approach 1.3, Pandolf et al. (1976) described a "packed" snow condition, and stated that their data indicate this, with little sinkage, but they did not provide a rationale. The added energy cost may be associated with slipperiness, though that is not stated in the paper. Looking at this plotted data (of $\eta$ and z), two data points are shown which have $z$ less than $5 \mathrm{~cm}$, and these have values of $\eta$ close to 1 .

- Pandolf et al. (1976) stated a correlation coefficient of 0.9 , but do not discuss what happens if the intercept ( 0 sinkage) is forced to 1.0.

- Eq. (9) results from comparing work rates on a treadmill to those obtained walking in actual snow. Nothing is reported regarding foot wear or clothing, with the exception of total weight carried, and whether or not the same clothing or boots were worn during each treadmill test.

Using data from Pandolf et al. (1976) and applying it to Eq. (3) to find $\eta$ resulted in two equations:

$\eta=2.6563+0.5767 z\left(\right.$ for $\left.V=0.67 m \cdot s^{-1}\right)$

$\eta=3.5763+0.1993 z\left(\right.$ for $\left.V=1.11 \mathrm{~m} \cdot \mathrm{s}^{-1}\right)$

At $V=0.67 \mathrm{~m} \mathrm{~s}^{-1}$ and $z=5 \mathrm{~cm}, \eta$ is 5.54 ; while at $V=1.11 \mathrm{~m} \mathrm{~s}^{-1}$ and $z=5 \mathrm{~cm}, \eta$ is 4.57 .

Using data from Pandolf et al. (1976) and applying it to Eq. (5) to find $\eta$ resulted in two additional equations:

$\eta=1.866+0.4051 z\left(\right.$ for $\left.V=0.67 \mathrm{~m} \cdot \mathrm{s}^{-1}\right)$

$\eta=3.0827+0.1718 z\left(\right.$ for $\left.V=1.11 \mathrm{~m} \cdot \mathrm{s}^{-1}\right)$

At $V=0.67 \mathrm{~m} \mathrm{~s}^{-1}$ and $z=5 \mathrm{~cm}, \eta$ is 3.89 ; while at $V=1.11 \mathrm{~m} \mathrm{~s}^{-1}$ and $z=5 \mathrm{~cm}, \eta$ is 3.94 . In this case, $\eta$ is higher for the higher velocity, but this only occurs at $z$ values less than $\sim 5.2 \mathrm{~cm}$ (where the two curves cross).

Pandolf et al. (1976) also provided the following equation:

$M=1.18+0.089 z$

where $M$ is the energy expenditure, in $\mathrm{W} /\left(\mathrm{kg} \cdot \mathrm{km} \cdot \mathrm{h}^{-1}\right)$. Alternatively:

$M=[1.18+0.089 z](W+L)\left[3.6 V \cos \left(\operatorname{atan}\left(\frac{G}{100}\right)\right]\right.$

where $M$ is whole body energy costs in watts; $V$ is in $\mathrm{m} \cdot \mathrm{s}^{-1}$ and $G$ is the grade as a percentage, although they did not report any testing on slopes. Additionally, this equation does not isolate/the static part of the metabolic rate associated with just standing with a load. The inclusion of a static term in the Pandolf et al. (1977) equation has been questioned recently (Ludlow \& Weyand, 2017), but data for those static costs was included in the 1977 paper, and a subsequent paper (Pimental and Pandolf, 1979).

Heinonen et al. (1959) correlated their walking in snow data with $z$, without presenting actual depth. Their tests were done at a natural walking pace (a curve fit to their averaged velocity data is in Fig. 3), and actual velocity and body weight was embedded in their energy cost (cal $\cdot \mathrm{kg}^{-1} \cdot \mathrm{m}^{-1}$ ). Pandolf et al. (1976) showed good agreement with that data at low $z$ values. However, Heinonen et al. (1959) showed a significant change in the slope of their data at $z$ values above $15 \mathrm{~cm}$. To accommodate that change related to $z$, they fitted two different straight lines to their data. Again, no density or snow strength $(\rho)$ data is provided. It is possible that the change in slope was caused by a heavier (more dense) snow, than what was available to Pandolf et al. (1976). The metabolic rate $(W)$ equation of Heinonen et al. (1959): 


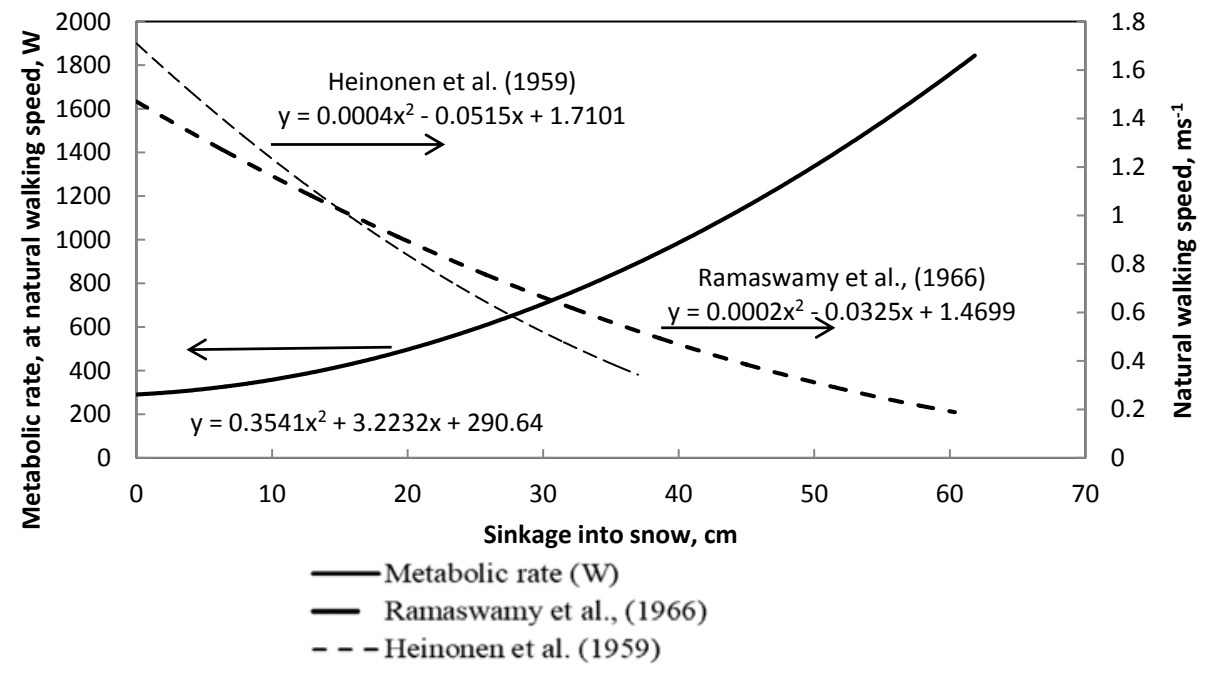

Fig. 3. Metabolic and walking speed curves based on Ramaswamy et al. (1966), additional walking speed curve from Heinonen et al. (1959).

$M=\left(10^{-0.1149+0.027 z}\right) 4.1868 W V$

where $W$ is mass $(\mathrm{kg})$ and $V$ is $\mathrm{m} \cdot \mathrm{s}^{-1}$ and $z$ is sinkage.

Ramaswamy et al. (1966) presented interesting work on energy consumption while walking in deep snow at natural walking speeds, including the effect of $z$ on walking velocity. They also reported that detailed data was available from the U.S. Library of Congress. Unfortunately, when this data was accessed, it is no longer legible (deteriorated fiche). Fig. 3 shows equations from Ramaswamy et al. (1966) based on digitization of their data plot, along with a curve fit of Heinonen et al. (1959) walking velocity data. It is important to note that as $z$ increases, natural walking velocity decreases due to a significant increase in metabolic rate. However, these decreases in moving velocity cannot fully compensate for the large increase in the/large energy requirements of moving through deep snow. The average subject mass reported was $58.9 \mathrm{~kg}$, carrying an additional $\sim 3 \mathrm{~kg}$ load over level ground. Individual clothing is probably not included in the value for body mass.

Smolander et al. (1989) examined the effect of work rate while walking in snow wearing three different boots $(0.9,1.9$ and $2.5 \mathrm{~kg})$ at self-determined/self-paced speeds $\left(0.47-1.07 \mathrm{~m} \mathrm{~s}^{-1}\right)$. They found no significant effect of wearing the heavy boots when walking in deep snow, but did note the strenuous work level required to walk in deep snow. Their snow $z$ data was shown in Fig. 2, which had an initial $\rho$ of 0.44 , an $h$ of $38.2 \mathrm{~cm}$, and an average $z$ of $26 \mathrm{~cm}$. Fig. 4 shows data from Smolander et al. (1989) (boot types 1,2, and 3 correspond to the weights above). Energy consumed (W) was determined using $\dot{V} \mathrm{O}_{2}$ and $\dot{V} \mathrm{CO}_{2}$ data, and the error bars shown are based on the standard deviation of the $\dot{V} \mathrm{O}_{2}$ and $\dot{V} \mathrm{CO}_{2}$ measurements. For walking in snow, the measured values are $\sim 12 \%$ higher than predicted by Eq. (2) with Eq. (6) for $\eta$ and Eq. (10). Equation (3), using Eqs. (10) and (11), with interpolation for $V$ significantly over predicts. Equation (5), with Eqs. (12) and (13), produces slightly closer values, but still over predicts. Comparing these data with Fig. 3 show that values from Smolander et al. (1989) are greater than values from Ramaswamy et al. (1966). Subjects from Smolander et al. (1989) wore their own loose-fitting clothing and long underwear (even during the treadmill tests), and this may explain why measured values were higher than the predicted treadmill values, i.e., the $\sim 12 \%$ differences mentioned above. Additional clothing layers has been shown to impose an increased metabolic rate during exercise that does not completely align with existing metabolic rate prediction methods (Dorman and Havenith, 2005; Teitlebaum and Goldman, 1972).

Based on a comparison to assess the influence of added mass alone and multi-layer ensembles, Teitlebaum and Goldman (1972) observed

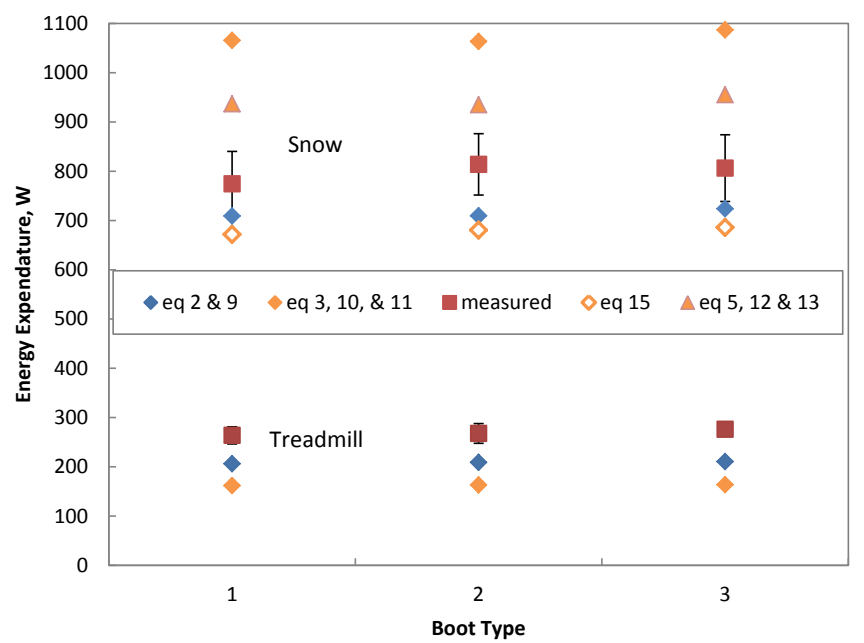

Fig. 4. Measured data of Smolander et al. (1989) compared with the Pandolf and Soule equations.

that the metabolic costs for wearing arctic ensembles to be greater than carrying the equivalent mass rather than worn. They concluded that the additional energy cost was related to the friction between layers or a "hobbling" effect of the additional clothing, something that was later also observed in following studies (Dorman and Havenith, 2005, 2009; Bach et al., 2017).

Rogers et al. (1965) had seven subjects walk in $13 \mathrm{~cm}$ deep snow ( $z$ $\sim 9 \mathrm{~cm}$ ) in boots, snowshoes, and skis, on a packed snow trail. They reported an average metabolic cost of $821 \mathrm{~W}$ in the undisturbed snow, and $342 \mathrm{~W}$ on the packed trail. Subjects averaged $70 \mathrm{~kg}$ mass, and had a walking velocity of $\sim 1 \mathrm{~m} \mathrm{~s}^{-1}$. They did not describe or report the masses of clothing or boots, but, it is worth noting that the value of $821 \mathrm{~W}$ is in close agreement with the data from Smolander et al. (1989) (Fig. 4).

Fig. 5 summarizes the data for walking in snow, with calculations for $\eta$, based upon Eq. (5). The dashed lines use values of velocity based on the natural walking speed equation from the corresponding source. Based on this comparison, it appears that the equations of Heinonen et al. (1959) (Eq. (16)), with their velocity equation from Fig. 3, is probably the most representative. 


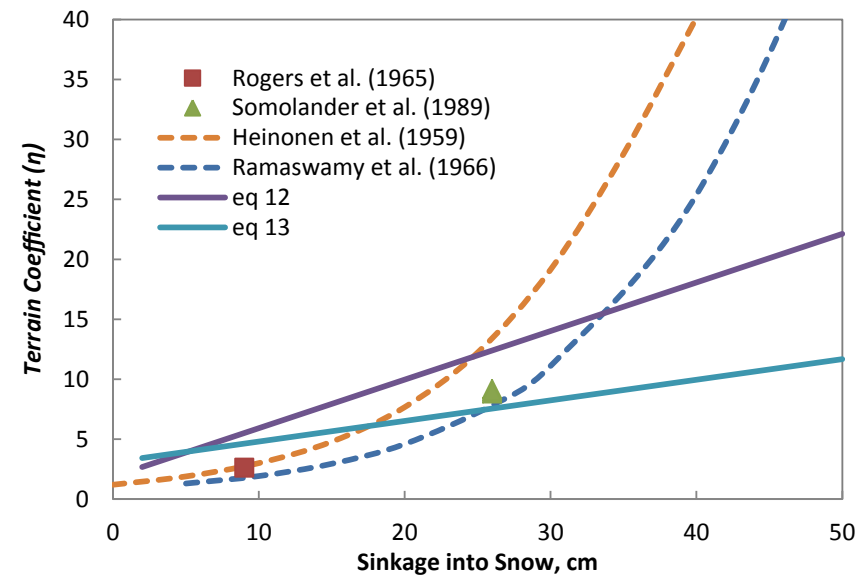

Fig. 5. Summary of snow data. Eqs. (12) and (13) are derived from a combination of Santee (Eq. (5)), Pandolf et al. (1976).

\subsection{Walking in snowshoes}

Knapik et al. (1996) present energy costs associated with walking on snow with four different types of snowshoes. They describe the snow as "about $8 \mathrm{~cm}$ of powder snow on a base of about $60 \mathrm{~cm}$ of crust ... the base had repeatedly frozen and thawed." Medial (mid-point of snow shoe) sinkage ranged from 4.1 to $6.1 \mathrm{~cm}$, with no significant difference between snowshoes. There were no non-snowshoe tests reported under the same conditions. They compared their results with Eq. (3), and (9), and assumed a $10 \%$ increase in energy per $\mathrm{kg}$ of snowshoe weight. Converting Eq. (3) to oxygen consumption rate, they reported Eq. (3) as under estimating oxygen consumption (and thus metabolic rate), by $3-16 \%$ depending on the snow shoe type.

Worsley et al. (1974) conducted trials of cold weather equipment and clothing that included energy expenditure experiments. They obtained the following equation for movement using snowshoes:

$M=-1.3+0.33 V$

where: $M$ is total energy cost $\left(\mathrm{ml} \mathrm{O} 2 \mathrm{~kg} \cdot \mathrm{min}^{-1}\right)$ and $V$ is velocity $\left(\mathrm{m} \cdot \mathrm{min}^{-1}\right)$; or

$M=-0.04355+6.633 \mathrm{~V}$

where: $M$ is total energy cost $\left(\mathrm{W} \cdot \mathrm{kg}^{-1}\right)$ and $V$ is velocity $\left(\mathrm{m} \cdot \mathrm{s}^{-1}\right)$.

Note that the energy cost is based on the individual's mass and entire fully kitted load/total load of equipment and clothing. Packs were carried, but the clothing and load values were not reported. The maximum snowshoe sinkage observed was $5 \mathrm{~cm}$.

Buskirk et al. (1956) presented an average value of $5.82 \mathrm{~W} \mathrm{~kg}^{-1}$ for snowshoeing, 6.29 for walking in snow, and 4.51 for walking on a road, at $1 \mathrm{~m} \mathrm{~s}^{-1}$. The average weight of the test subjects was $75.9 \mathrm{~kg}$, and their clothing weighed $9.76 \mathrm{~kg}$. However, they did not provide details on the snowshoes, or mention details regarding extra load, if any, was carried during the marches. No information was given on the snow cover or slope.

Allen and O'Hara (1973) obtained an average energy expenditure of $337 \pm 105 \mathrm{~W}$ based on nine subjects carrying 50-60 lbs (23-27 kg) on snowshoes. This was part of an overall study of energy expended during infantry patrols in the arctic. Average subjects' weight was not provided.

Table 1 presents a summary of the snowshoe data, and estimates of $\eta$ (using Eq. (5)), which are fairly consistent, except for one negative slope value.

\section{Summary - a new snow coefficient}

The general equation recommended for walking in the snow (Table 2) is based on Fig. 5, and the equation of Heinonen et al. (1959).
The value for $z(\mathrm{~cm})$ is for sinkage into the snow. Energy requirements for walking in snow are very dependent on velocity and sinkage values. The equation from Fig. 3 should be used to estimate the natural walking speed in snow $(V)$, and the equation for $z(\mathrm{~cm})$ to estimate sinkage based on the snow depth and density. The snowshoe $\eta$-value assumes relatively consistent, and limited, sinkage for all snow conditions.

\section{Discussion}

Terrain coefficients: It is intuitively understood 1) a thin layer of hard packed snow can be slippery, 2) it's harder to walk or drive through deeper snow, and 3) differences in moisture content and volumes can cause snow to seem heavy or light, and easier or harder to compact. Terrain coefficients $(\eta)$ are important because they take those observed effects of snow, and other surface related effects, to the next step, quantifying the impact of those surfaces in terms of energy costs.

The original values for $\eta$ were derived empirically from a limited set of data, and there was no apparent effort to relate the values to the physical properties of the surface/substrates. One exception is the Pandolf et al. (1976) snow equation (Eq. (9)) for $\eta$, which accounted for sinkage. This paper further illustrates how incorporating the physical properties of the different surfaces requires separate equations and surface specific inputs. Tables 1 and 2 summarize the results for snowshoes and Table 2 for more general snow applications. Note that to incorporate better terrain coefficient values requires more information of the surface properties of snow. An important issue is thus the availability of that information, by observation, ground measurements or the analysis of remote imagery, whether an Unmanned Aerial Vehicle (UAV) or satellite.

This paper is an extension of Richmond et al. (2015) which updated terrain factors for surfaces provided by Soule and Goldman (1972) for paved and gravel roads, sand, swamp, and brush (vegetation). That paper differentiated between gravel and "dirt" roads, and added information for slippery terrain (i.e. packed wet clay and ice). The paper introduces the use of cone values, a measurement for assessing surfaces for vehicle mobility (FM 5-430-00-1 (1994)), for calculating silt, clay and swamp $\eta$ values, but presents simple equations for all of the $\eta$ values. The energy requirements for walking in snow are dependent on velocity and sinkage. Thus, the terrain factor for snow presented in this paper differs in the use of a different equation for velocity $(V)$ and the use of a $z$ value to represent sinkage into snow. To a degree, the terrain factor for snow can be approximated if the nature of the forecast snowfall, in terms of depth and moisture content, is known, but the extension of the snow terrain factor to the use of forecast data unfortunately beyond the scope of this paper.

Next generation terrain coefficients: As indicated earlier, this paper demonstrates the importance of multi-disciplinary science by incorporating information and knowledge from the disciplines of physiology, biomechanics, geology or soil science, and civil engineering. Unfortunately there apparently has not been any direct attempt made to link biomechanics to the terrain coefficient - although the work of Voloshina et al. (2012) and Looney et al. (2018a) indicates clear potential for future changes. In addition, it would be expected that the physical properties footwear soles would impact the interface of the foot with the ground, and the interaction of different soles and surfaces would alter the terrain effects. Military footwear evaluations conducted at Natick Research Development and Engineering Center incorporate a measurement of the friction between boot soles and simulated surfaces, and one future project may be to link footwear sole properties and terrain properties.

A terrain coefficient for snow is just one factor or variable in the overall effort to model and predict the thermal state and performance limits of individuals and population. It should be possible to improve the snow coefficient by taking into consideration the interaction on snow properties of moisture content, air and ground temperatures, and wind effects such as blow, drifting, and packing. Freeze-thaw cycles and 
Table 1

Summary of snowshoe data.

\begin{tabular}{|c|c|c|c|c|c|c|}
\hline Source & $\begin{array}{l}\text { Metabolic Rate } \\
\text { (W) }\end{array}$ & $\begin{array}{l}\text { Velocity } \\
\left(\mathrm{m} \cdot \mathrm{s}^{-1}\right)\end{array}$ & Weight (kg) & Load (kg) & Slope & $\eta$ based on Eq. (5) \\
\hline \multirow[t]{2}{*}{ Knapik et al. (1996) } & 551 & 1.11 & 73 & 2.3 & $2.4 \%$ & 3.2 \\
\hline & 444 & & & & $-2.4 \%$ & 2.2 (with Eq. (5)) \\
\hline $\begin{array}{l}\text { Worsley et al. } \\
\text { (1974) }\end{array}$ & 413 & 1.0 & 66.7 & $\begin{array}{l}\text { Not reported, but included in Eq. (15), Subject Weight } \\
\text { only used to calculate metabolic rate in this table }\end{array}$ & Not Reported & $\begin{array}{l}2.8 \text { (assuming } 0 \% \text { slope } \\
\text { and } 0 \mathrm{~kg} \text { load) }\end{array}$ \\
\hline Buskirk et al. (1956) & 499 & 1.0 & 75.9 & 9.76 & Not reported & 2.6 (assuming $0 \%$ slope) \\
\hline $\begin{array}{l}\text { Allen and O'Hara } \\
\text { (1973) }\end{array}$ & 337 & $0.56-1.0$ & Not reported & $23-27$ & Level to hilly & Cannot be calculated \\
\hline
\end{tabular}

Table 2

Recommended Values for $\eta$ for use in Eq. (5).

\begin{tabular}{ll}
\hline Terrain Description & \\
\hline Walking with snowshoes & $\eta=2.7$ \\
Walking in Snow & $\eta=0.0005 z^{3}+0.0001 z^{2}+0.1072 z+1.2604$ \\
Where: & $V=0.0004 z^{2}-0.0515 z+1.7101$ \\
Input for walking speed & $z=h\left(1-\frac{\rho_{0}}{1.186}\right)$ \\
Snow depth & \\
\hline
\end{tabular}

solar radiation may also effect the formation of a crust. With an adequate understanding of these interactions, and good local forecast data, it may be possible to more accurately project how snow properties effects humans. However, to build a comprehensive model, a simulation of the complete effect of weather, terrain and activity on individuals or groups in the cold, requires far more than just a terrain coefficient for snow.

The terrain factor is a relatively simple construct to represent the important characteristics of snow relative to human activities for application in a more complex model. There is an importance to developing more comprehensive biophysical and physiological models based on energy costs of activities and the rate of energy exchanges with the body and with the external environment (Potter et al., 2017; Xu and Tikuisis, 2014). All of the factors that contribute to the physical properties of snow, plus clothing, the nature and cycle of activities, nutrition, injuries and other individual physical and physiological characteristic influence the health and well-being of an individual in the cold (Potter et al., 2018a).

Human factors may also require more refinements of terrain coefficients. There is a tendency to favor simple, universal equations and indexes, and linear or simple power functions, but living organisms have critical limits determined by both the biomechanics of anatomy and physiology. A faster, more rugged or innovative vehicle can be built, and fitted with a more powerful engine, to overcome terrain, but humans and other organism are limited by anatomy and physiology. The human factor with snow may also be modified by taking into account the interaction of anatomy with snow depth (z). An alternative analysis of the Pandolf et al. (1976) data suggests a more complex function with inflection points that may correspond to anatomical landmarks.

An appreciation of the complexity of a comprehensive model or simulation of exposure to cold conditions should serve to temper any tendency to place complete reliance on any model to fully replace the human judgement in planning and operations. There will always be a place for experience and judgment on the part of the individual and leadership to live and function in the cold. Each model, or an aggregate of models into a simulation, is just a tool to support human decision making.

\section{Conclusion}

Predicting the energy costs of human travel over snow is of important for planning dismounted travel under snowy conditions. Terrain factors $(\eta)$ are used to adjust predictive energy costs models for different surface conditions, including snow. Data from prior human studies, and knowledge of snow characteristics, and from studies of vehicular travel in snow, were used to derive two new snow coefficients (Table 2).

One coefficient, based on an estimate of walking in the snow without snowshoes is based on compressed snow depth (z), which in turn can be estimated from uncompressed snow depth (h) and snow strength $(\rho)$. An equation to estimate walking speed $(V)$ for a given $z$ is also provided. The second coefficient is a value for walking on snowshoes.

The coefficients are for use in the Pandolf equation (Pandolf et al., $1977)$ which estimates total energy costs $(M)$ during walking in Watts. In turn, estimates of $M$ be entered into thermal models to predict body temperatures (Potter et al., 2017) and potentially vice versa (Welles et al., 2018a).

Models, including components such as terrain coefficients, will continue to be refined as more snow and human data becomes available and better methods of analysis are developed, but model users must be cognizant of the limitations of models. It is important to note that these models represent static tools meant to describe a general response for a given population, as such they should not be seen as a method that overrides the value of individualized predictors (e.g., age, fitness) or real-time measures (e.g., gait, core temperature). While modeling methods provide quantitative guidance for planning purposes, to obtain the most meaningful information, individualized and real-time direct measures (e.g., wearables) (Tharion et al., 2013) and/or the combination of real-time algorithms (e.g., core temperature estimations, GPSderived adjustments) (Lin et al., 2018; Looney et al., 2018b; Parker et al., 2017; Potter et al., 2018b; Welles et al., 2018b) should be sought. Over-reliance on models in extreme physical environments without human judgement can be dangerous.

\section{Author contributions}

Conceived and designed experiments and analytical structure: PWR WRS. Analyzed the data: PWR AWP WRS. Wrote the paper: PWR AWP WRS DPL.

\section{Acknowledgements}

This research was supported in part by appointments to the Knowledge Preservation Program of Dr. Richmond at the U.S. Army 
Engineer Research and Development Center, Cold Regions Research and Engineering Laboratory and Dr. Santee at the U.S. Army Research Institute of Environmental Medicine administered by the Oak Ridge Institute for Science and Education through an interagency agreement between the U.S. Department of Energy and ERDC-CRREL.

\section{References}

Allen, C.J., O'Hara, W.J., 1973. Energy Expenditure of Infantry Patrols during and Arctic Winter Exercise. CCIEM Report No. 73-R-985. Defence and Civil Institute of Environmental Medicine, Defense Research Board, Department of National Defence, Canada.

Bach, A.J., Costello, J.T., Borg, D.N., Stewart, I.B., 2017. The Pandolf load carriage equation is a poor predictor of metabolic rate while wearing explosive ordnance disposal protective clothing. Ergonomics 60 (3), 430-438.

Baker-Fulco, C.J., 1995. Overview of dietary intakes during military exercises. In: Marriott, M.B. (Ed.), Not Eating Enough: Overcoming under Consumption of Military Rations. National Academy Press, Washington D.C., pp. 121-149.

Buskirk, E. R., Kreider, M., Brebbia, R, Morana, N., Daniels, F, et al, 1956. Caloric Intake and Energy Expenditure in a Sub-arctic Environment. Quartermaster Research and Development Center, Environmental Protection Division, Natick, MA Technical Report EP-33, Headquarters.

Day, D.S., Young, A.J., Askew, E.W., 2012. Chapter 6. Nutrition and military performance. In: Friedl, K.E., Santee, W.R. (Eds.), Quantitative Physiology. Borden Institute. US Army Medical Research and Material Command, Ft. Detrick, MD, pp. $157-204$.

Dorman, L.E., Havenith, G., 2005. The influence of clothing weight and bulk on metabolic rate when wearing protective clothing. In: Proceedings of the 3rd International Conference on Human-environmental System; September; Tokyo, Japan, pp. 47-50.

Dorman, L.E., Havenith, G., 2009. The effects of protective clothing on energy consumption during different activities. Eur. J. Appl. Physiol. 105 (3), 463-470. https:// doi.org/10.1007/s00421-008-0924-2.

Givoni, B., Goldman, R.F., 1971. Predicting metabolic energy cost. J. Appl. Physiol. 30 (3), 429-433.

Headquarters, Department of the Army, 1994. Planning and design of roads, airfields, and heliports in the theater of operations - road design. Field Man FM 5-430-00-1.

Haehnel, R.B., Shoop, S.A., 2004. A macroscale model for low density snow subjected to rapid loading. Cold Reg. Sci. Technol. 40 (2004), 193-211.

Heinonen, A.O., Karvones, M.J., Ruosteenoja, R., 1959. The energy expenditure of walking on snow at various depths. Ergonomics 2 (4), 389-394. https://doi.org/10. 1080/00140135908930455.

Knapik, J., Harman, E.A., Reynolds, K.L., 1996. Load carriage using packs: a review of physiological, biomechanical and medical aspects. Appl. Ergon. 27, 207-216.

Lin, J.H., Kirlik, A., Xu, X., Chen, J., Or, C., Deb, S., ... Madathil, K.C., 2018. New Technologies in Human Factors and Ergonomics Research and Practice. Applied Ergonomics.

Looney, D.P., Santee, W.R., Karis, A.J., Blanchard, L.A., Rome, M.N., Carter, A.J., Potter, A.W., 2018a. Metabolic costs of military load carriage over complex terrain. Mil. Med usx099. https://doi.org/10.1093/milmed/usx099.

Looney, D.P., Buller, M.J., Gribok, A., Welles, A.P., Leger, J.L., Potter, A.W., Rumpler, W.V., Tharion, W.J., Hoyt, R.W., 2018b. Estimating resting core temperature using heart rate. J. Meas. Phys. Behav. 1 (2), 79-86.

Ludlow, L.W., Weyand, P.G., 2017. Walking economy is predictably determined by speed, grade, and gravitational load. J. Appl. Physiol. 123 (5), 1288-1302.

Pandolf, K.B., Haisman, M.F., Goldman, R.F., 1976. Metabolic energy expenditure and terrain coefficients for walking on snow. Ergonomics 19 (6), 683-690. https://doi. org/10.1080/00140137608931583.

Pandolf, K.B., Givoni, B., Goldman, R.F., 1977. Predicting energy expenditure with loads while standing or walking very slowly. J. Appl. Physiol. 43, 577-581.

Parker, R., Vitalis, A., Walker, R., Riley, D., Pearce, H.G., 2017. Measuring wildland fire fighter performance with wearable technology. Appl. Ergon. 59, 34-44.
Pimental, N.A., Pandolf, K.B., 1979. Energy expenditure while standing or walking slowly uphill or downhill with loads. Ergonomics 22 (8), 963-973. https://doi.org/10.1080/ 00140137908924

Potter, A.W., Blanchard, L.A., Friedl, K.E., Cadarette, B.S., Hoyt, R.W., 2017. Mathematical prediction of core body temperature from environment, activity, and clothing: the heat strain decision aid (HSDA). J. Therm. Biol. 64, 78-85.

Potter, A.W., Gonzalez, J.A., Carter, A.J., Looney, D.P., Rioux, T.P., Srinivasan, S., Sullivan-Kwantes, W., Xu, X., 2018a. Comparison of Cold Weather Clothing Biophysical Properties: US Army, Canadian Defence and Norwegian Military. US Army Research Institute of Environmental Medicine, Natick, MA, 01760, USA Technical Report, T18-02.

Potter, A.W., Santee, W.R., Mullen, S.P., Karis, A.J., Blanchard, L.A., Rome, M.N., Pitts, K.P., Looney, D.P., 2018b. Complex Terrain Load Carriage Energy Expenditure Estimation Using GPS Devices. Medicine \& Science in Sports \& Exercise (MSSE).

Ramaswamy, S.S., Dua, G.L., Raizada, V.K., Dimri, G.P., Viswanathan, K.R., Madhaviah, J., Srivasava, T.N., 1966. Effect of looseness of snow on energy expenditure in marching on snow-covered ground. J. Appl. Physiol. 21 (6), 1747-1749.

Richmond, P.W., 1984. Conventional Land Mines in Winter. U.S. Army Cold Regions Research and Engineering Laboratory, Hanover, NH CRREL Special Report 84-30.

Richmond, P.W., Shoop, S.A., Blaisdell, G.L., 1995. Cold Regions Mobility Models. U.S. Army Cold Regions Research and Engineering Laboratory, Hanover, NH CRREL Technical Report 95-1.

Richmond, P.W., 1995. Motion Resistance of Wheeled Vehicles in Snow. U.S. Army Cold Regions Research and Engineering Laboratory, Hanover, NH CRREL Technical Report 95-7.

Richmond, P.W., Potter, A.W., Santee, W.R., 2015. Terrain factors for predicting walking and load carriage energy costs: review and refinement. J. Sport Hum. Perform. 3 (3), $1-26$.

Rogers, T.A., Buck, A.C., Klopping, J.C., 1965. Studies on the Energy Cost of Level Crosscountry Travel in the Arctic. Arctic Aeromedical Laboratory, Air Force Systems Command, Ft. Wainwright, AK Report AAL-TR65-9.

Santee, W.R., Blanchard, L.A., Speckman, K.L., Gonzalez, J.A., Wallace, R.F., 2003. Load Carriage Model Development and Testing with Field Data. U.S. Army Research Institute of Environmental Medicine, Natick, MA Technical Note No. TN03-3.

SIPRE, 1954. Instructions for Making and Recording Snow Observations, Instruction Manual 1, Snow, Ice, and Permafrost Research Establishment (SIPRE). U.S. Army Corps of Engineers, Wilmette, IL.

Soule, R.G., Goldman, R.F., 1972. Terrain coefficients for energy cost prediction. J. Appl. Physiol. 32 (5).

Smolander, J., Louhevaara, V., Hakola, T., Ahonen, E., Klen, T., 1989. Cardiorespiratory strain during walking in snow with boots of differing weights. Ergonomics 32 (1), 3-13. https://doi.org/10.1080/00140138908966063.

Teitlebaum, A., Goldman, R.F., 1972. Increased energy cost with multiple clothing layers. J. Appl. Physiol. 32 (6).

Tharion, W.J., Potter, A.W., Duhamel, C.M., Karis, A.J., Buller, M.J., Hoyt, R.W., 2013. Real-time physiological monitoring while encapsulated in personal protective equipment. J. Sport Hum. Perform. 1 (4), 14-21.

Voloshina, A.S., Kuo, A.D., Daley, M.A., Ferris, D.P., 2012. Biomechanical and energetic consequences of walking on uneven terrain. In: Presented at the Dynamic Walking Conference May 2012, Pensacola, FL, . http://dynamicwalking.org/dw2012/, video of presentation. http://www.youtube.com/watch?v $=$ dfPNUGlBd5A and extended abstract. http://www.ihmc.us/dwc2012files/Voloshina.pdf.

Welles, A.P., Buller, M.J., Looney, D.P., Rumpler, W.V., Gribok, A.V., Hoyt, R.W., 2018a. Estimation of metabolic energy expenditure from core temperature using a human thermoregulatory model. J. Therm. Biol. 72, 44-52.

Welles, A.P., Xu, X., Santee, W.R., Looney, D.P., Buller, M.J., Potter, A.W., Hoyt, R.W., 2018b. Estimation of core body temperature from skin temperature, heat flux, and heart rate using a Kalman filter. Comput. Biol. Med. 99, 1-6.

Worsley, D., Amor, A., Hughes, W.P., Ince, N., Ramsay, D., 1974. Physiological Trial of Cold Weather Clothing and Equipment, Exercise Honky Tonk I, Norway, 1974. Report APRE No. 16/74. Army Personnel Research Establishment, Ministry of Defence, Royal Aircraft Establishment, Farnborugh, Hants, England.

Xu, X., Tikuisis, P., 2014. Thermoregulatory modeling for cold stress. Compr. Physiol. 


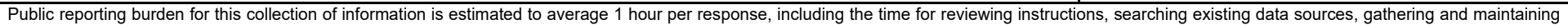

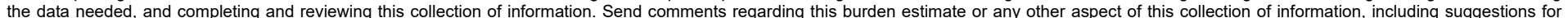

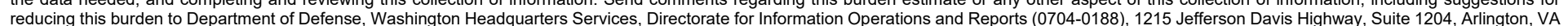

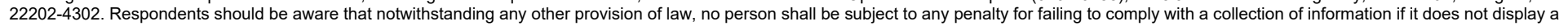
currently valid OMB control number. PLEASE DO NOT RETURN YOUR FORM TO THE ABOVE ADDRESS.
1. REPORT DATE (DD-MM-YYYY)
August 2021

4. TITLE AND SUBTITLE

Terrain coefficients for predicting energy costs of walking over snow
3. DATES COVERED (From - To)

5a. CONTRACT NUMBER

5b. GRANT NUMBER

5c. PROGRAM ELEMENT NUMBER

5d. PROJECT NUMBER

5e. TASK NUMBER

5f. WORK UNIT NUMBER

8. PERFORMING ORGANIZATION REPORT NUMBER

ERDC/CRREL MP-21-19

10. SPONSOR/MONITOR'S ACRONYM(S)

USACE

11. SPONSOR/MONITOR'S REPORT NUMBER(S)

\section{DISTRIBUTION / AVAILABILITY STATEMENT}

Approved for public release; distribution is unlimited.

\section{SUPPLEMENTARY NOTES}

This article was originally published online in Applied Ergonomics on 15 August 2018.

This research was supported in part by appointments to the Knowledge Preservation Program of Dr. Richmond at the U.S. Army Engineer Research and Development Center, Cold Regions Research and Engineering Laboratory and Dr. Santee at the U.S. Army Research Institute of Environmental Medicine administered by the Oak Ridge Institute for Science and Education through an interagency agreement between the U.S. Department of Energy and ERDC-CRREL

\section{ABSTRACT}

Predicting the energy costs of human travel over snow can be of significant value to the military and other agencies planning work efforts when snow is present. The ability to quantify, and predict, those costs can help planners determine if snow will be a factor in the execution of dismounted tasks and operations. To adjust predictive models for the effect of terrain, and more specifically for surface conditions, on energy costs, terrain coefficients ( $\eta$ ) have been developed.

By applying knowledge gained from prior studies of the effects of terrain and snow, and by leveraging those existing dismounted locomotion models, we seek to outline the steps in developing an improved terrain coefficient ( $\eta$ ) for snow to be used in predictive modeling. Using published data, methods, and a well-informed understanding of the physical elements of terrain, e.g., characterization of snow sinkage (z), this study made adjustments to n-values specific to snow.

This review of published metabolic cost methods suggest that an improved n-value could be developed for use with the Pandolf equation, where $\mathrm{z}=\operatorname{depth}(\mathrm{h}) *(1-($ snow density $(\rho 0) / 1.186))$ and $\mathrm{\eta}=0.0005 \mathrm{z} 3+0.0001 \mathrm{z} 2+0.1072 \mathrm{z}+1.2604$. This paper provides data-driven improvements to models that are used to predict the energy costs of dismounted movements over snow.

\section{SUBJECT TERMS}

Metabolic costs, Physiology, Military, Load carriage

\section{SECURITY CLASSIFICATION OF:}

\section{a. REPORT}

Unclassified

b. ABSTRACT
Unclassified

\section{c. THIS PAGE}

Unclassified
17. LIMITATION OF ABSTRACT

UU
18. NUMBER OF PAGES

13 19a. NAME OF RESPONSIBLE PERSON

19b. TELEPHONE NUMBER (include area code) 
Cold Regions Research and Engineering Laboratory U.S. Army Engineer Research and Development Center 3909 Halls Ferry Road

Vicksburg, MS 39180

Biophysics and Biomedical Modeling Division United States Army Research Institute of Environmental Medicine Natick, MA 01760

Oak Ridge Institute for Science and Education (ORISE) 1299 Bethel Valley Road

Oak Ridge, TN 37830 